\title{
WEST NILE VIRUS - A NEW INFECTION IN THE SLOVAK REPUBLIC?
}

\author{
Erik Dorko', Andrea Bušová1, Tomáš Csank², Eva Feketeová3, Kvetoslava Rimárová', Jana Diabelková1, \\ Róbert Čellár ${ }^{4}$, Matúš Bereš ${ }^{4}$, Miklós Gyuranecz ${ }^{5}$, Juraj Pistl², Tamás Bakonyi6 ${ }^{6,7}$, Andrej Jenča Jr. ${ }^{8}$, \\ Janka Jenčová ${ }^{8}$, Adriána Petrášová $^{8}$ \\ ${ }^{1}$ Department of Public Health and Hygiene, Faculty of Medicine, Pavol Jozef Šafárik University in Košice, Košice, Slovak Republic \\ 2Department of Microbiology and Immunology, University of Veterinary Medicine and Pharmacy, Košice, Slovak Republic \\ ${ }^{3}$ Department of Neurology, Faculty of Medicine, Pavol Jozef Šafárik University in Košice and Louis Pasteur University Hospital, Košice, Slovak \\ Republic \\ ${ }^{4}$ Department of Orthopaedics and Traumatology of Locomotory Apparatus, Faculty of Medicine, Pavol Jozef Šafárik University in Košice and \\ Louis Pasteur University Hospital, Košice, Slovak Republic \\ ${ }^{5}$ Institute for Veterinary Medical Research, Centre for Agricultural Research, Hungarian Academy of Sciences, Budapest, Hungary \\ ${ }^{6}$ Department of Microbiology and Infectious Diseases, University of Veterinary Medicine, Budapest, Hungary \\ ${ }^{7}$ Viral Zoonoses, Emerging and Vector-Borne Infectious Group, Institute of Virology, University of Veterinary Medicine, Vienna, Austria \\ ${ }^{8}$ Department of Stomatology and Maxilofacial Surgery, Faculty of Medicine, Pavol Jozef Šafárik University in Košice and Louis Pasteur \\ University Hospital, Košice, Slovak Republic
}

\section{SUMMARY}

Objective: The aim of the study was to evaluate the seroprevalence of West Nile virus (WNV) among the variable population of Eastern Slovakia.

Methods: A serologic survey was conducted using 464 serum samples. The basic demographic, epidemiologic and clinical information was obtained for each serum sample at the time of specimen collection. The presence of antibodies against WNV was investigated using a commercial enzyme-linked immunosorbent assay (ELISA). All the ELISA positive samples were further analysed by a neutralization test with WNV and Usutu virus.

Results: Three serum samples $(0.65 \%)$ from the participants $(\mathrm{N}=464)$ were considered positive for antibodies to WNV. A 29-year-old female was repeatedly exposed to mosquito bites working as a shepherdess and participating in many outdoor activities. Two other females (61 and 76 years old) were treated at the Department of Neurology due to monoparesis of the upper extremity, vertigo; both had a significant epidemiological history with frequent tick and mosquito bites and stay in an endemic region.

Conclusions: Although there was no evidence of WNV infection in the Slovak Republic, the epidemiological situation in the neighbouring countries warrants vigilance and appropriate measures, including the introduction of specific diagnostic tools into clinical practice. The constant monitoring of birds and mosquitoes also seems necessary.

Key words: West Nile virus, mosquitoes, seroprevalence

Address for correspondence: E. Feketeová, Department of Neurology, Faculty of Medicine, Pavol Jozef Šafárik University in Košice and Louis Pasteur University Hospital, Trieda SNP 1, 04011 Košice, Slovak Republic. E-mail: eva.feketeova@upjs.sk

https://doi.org/10.21101/cejph.a5287

\section{INTRODUCTION}

West Nile virus (WNV), a single-strand RNA virus, is a mosquito-borne zoonotic arbovirus, which belongs to the family Flaviviridae, genus Flavivirus $(1,2)$.

WNV circulates in an enzootic cycle, with wild and domestic birds as well as mosquitoes as the main amplifying hosts. Ornithophilic mosquitoes, especially of the Culex species, are competent for WNV transmission (3).

Mosquitoes get the infection by feeding on viraemic birds. Once infected, the mosquito remains infectious throughout its life, potentially transmitting the virus to every vertebrate on which it feeds (4). Humans, horses and other mammals are accidental and dead-end hosts, since they do not develop a viraemic titre sufficient to infect mosquitoes and amplify the transmission cycle (5).

WNV was first isolated in 1937 from the blood of a woman suffering a febrile illness in the West Nile district of Uganda (6-8).

In recent years, the spread of WNV has been observed worldwide, and several outbreaks have also been recorded in Europe (9). The presence of WNV infection has been reported in such European countries as Greece, France, Romania, Italy, Portugal, and Spain, as well as in Slovakia's direct neighbours: the Czech Republic, Poland, Austria, Hungary, and Ukraine (7).

The main mode of WNV transmission is by the bite of an infected mosquito (10), though other rare but reported routes 
of transmission in humans include organ transplantation, blood transfusion and transplacental transmission (11).

Infection with WNV in humans is generally asymptomatic in most cases, while in approximately $20 \%$ of cases it results in West Nile fever (WNF) and in less than $1 \%$ acute West Nile neuroinvasive disease (WNND). Symptoms of WNF include fever, headache, tiredness, body aches, nausea, vomiting, joint pains, occasionally with a skin rash and swollen lymph glands. WNND is characterized by signs of encephalitis, meningoencephalitis or meningitis and long-term sequelae like altered mental status, lethargy, cranial nerve palsies, acute flaccid paralysis and movement disorders $(1,4,8,12,13)$.

The main objective of this preliminary study was to determine the seroprevalence of antibodies to WNV and to investigate whether any relationship exists between serostatus and the related risk factors.

\section{MATERIALS AND METHODS}

Blood samples were taken by venepuncture, by which $10 \mathrm{ml}$ of venous blood was obtained. Blood serum was then separated by centrifugation and stored at $-70{ }^{\circ} \mathrm{C}$ until laboratory analysis.

Each participant who signed informed consent for the study filled-out a questionnaire. Basic demographic, epidemiological and clinical data were collected at the time of specimen collection.

The blood serum samples were examined for the presence of anti-WNV IgG/M antibodies by commercial blocking ELISA kits (INGEZIM West Nile COMPAC, INGENASA, Spain) following the manufacturer's instructions. Samples were considered to be positive when the inhibition percentage (IP) was $\geq 40 \%$ and negative when the IP was $\leq 30 \%$. Samples with IP between 30 and $40 \%$ were considered doubtful. All samples with positive results were further analysed by a serum neutralization test with WNV and Usutu virus (USUV), where an obtained titre of 1:10 or more was considered a positive result (14).

Statistical analyses were performed using the statistical software program IBM SPSS version 21.0. The demographic

Table 1. Demographic characteristics of study participants $(N=464)$

\begin{tabular}{|l|c|c|c|}
\hline \multicolumn{2}{|c|}{} & $\mathbf{n}$ & $\%$ \\
\hline \multirow{3}{*}{ Age (years) } & $0-39$ & 171 & 36.9 \\
\cline { 2 - 4 } & $40-59$ & 155 & 33.4 \\
\cline { 2 - 4 } & $60+$ & 138 & 29.7 \\
\hline \multirow{4}{*}{ Population group } & Patients & 265 & 57.1 \\
\cline { 2 - 4 } & Soldiers & 103 & 22.2 \\
\cline { 2 - 4 } & Roma & 45 & 9.7 \\
\cline { 2 - 4 } & Gardeners & 31 & 6.7 \\
\cline { 2 - 4 } & Agricultural employees & 20 & 4.3 \\
\hline \multirow{3}{*}{ Gender } & Male & 265 & 57.1 \\
\hline \multirow{2}{*}{ Residence type } & Female & 199 & 42.9 \\
\cline { 2 - 4 } & Urban & 230 & 49.5 \\
\cline { 2 - 4 } & Rural & 234 & 50.5 \\
\hline
\end{tabular}

data were described using descriptive statistics as medians with standard deviations.

\section{RESULTS}

\section{Clinical Characteristics}

A total of 464 serum samples were tested for the presence of WNV antibodies using an ELISA assay. The mean age of the 464 enrolled patients was $49.2 \pm 18.1$ years; 265 patients were males $(57.1 \%$, mean age $44.9 \pm 16.4$ years $)$, and 199 were females $(42.9 \%$, mean age $54.9 \pm 18.7$ years $)$. Table 1 presents the demographic characteristics of the study participants. The explored sample consisted of 31 gardeners, 103 soldiers, 20 farm operators, 45 persons of Roma ethnicity, and 265 patients admitted to the Departments of Neurology $(n=126)$ and Orthopaedics and Traumatology of Locomotory Apparatus $(n=139)$.

\section{Presence of Anti-WNV IgG/M Antibodies}

Three serum samples $(0.65 \%)$ of the participants were considered positive based on the above-mentioned protocol.

\section{Case 1}

A 29-year-old female from the Snina area worked as a shepherdess. In her personal history she mentioned active gardening and work in the forest; she did not confirm tick bites; however, she did report repeated mosquito bites accompanied by a strong skin reaction. She used to consume raw milk (cow, goat, ovine) and its products. In the past she was diagnosed and treated for rheumatoid and neurological diseases, complained about longlasting fatigue connected with cold feet and hands syndrome. Travel history was not significant, and she had not undergone vaccination against flaviviruses.

\section{Case 2}

A 61-year-old female lived in the countryside (Košice area), preferring outdoor activities such as gardening and hiking. She was bitten several times by ticks and mosquitoes, accompanied by local signs of inflammation and itching. She used to consume raw milk (cow, goat, ovine) and its products, keeping the animals at a small family farm; she several times visited Hungary and had not been vaccinated against tick-borne encephalitis. No significant febrile illness was mentioned in her records.

The female patient was admitted to the Department of Neurology (September 2014) due to monoparesis of the left upper extremity (UE). Subjective spells (irradiating pain from the neck to the 3rd and 4th finger, progressive weakness of the limb and muscle volume reduction) had been going on for several years at the time of admission. Objective examination showed mild paresis of the left UE and hand amyotrophy, increased deep tendon reflexes on the left UE, together with the present features of flaccid- peripheral and central paresis of the UE. Electromyography - a conduction study confirmed axonal lesion of the nervus ulnaris and a needle study revealed neurogenic damage to the examined muscles. Magnetic resonance imaging of the brain showed unspecified demyelinating lesions in the 
white matter resulting from an unspecified small-vessel disease; protrusions of the intervertebral discs $\mathrm{C} 4 / 5, \mathrm{C} 5 / 6$ and $\mathrm{C} 6 / 7$ were found in the cervical spinal cord. The disc protrusions tended to compress the right-side structures of the spinal channel and did not explain the clinical findings. The analgetic treatment and physiotherapy provided slightly suppressed the pain symptoms and the finding was left for neurological surveillance. The patient's serum sample showed cross reactivity with USUV.

\section{Case 3}

A 76-year-old female patient came from the area of Kralovsky Chlmec. The patient was admitted to the Department of Neurology because of acute worsening of chronic vertigo based on osteoarthritic changes of the cervical area and atherosclerotic changes of the vertebrobasilar supply. She was diagnosed and treated for ischaemic heart disease, chronic renal disease, nephrolithiasis, back pain syndrome, arterial hypertension, and hypothyreosis. From the epidemiological point of view, she had been bitten by the ticks and mosquitoes, was living in Austria and kept animals.

The patient's serum sample revealed IgG antibodies to the tick-borne encephalitis virus, and the patient had not been vaccinated against it.

\section{DISCUSSION}

According to Annual Reports of the Public Health Authority, no human cases of West Nile fever have thus far been reported in Slovakia (15).

Three positive serum samples were detected in the presented study, which shows a prevalence of $0.65 \%$. Similarly, Gaibani et al. (9) rated the seroprevalence in healthy blood donors residing in the metropolitan area of Milan at $0.57 \%$. The low proportion of positivity in this study could be explained by the relatively small sample size $(n=464)$ and the local nature of the study, which was focused on Eastern Slovakia. It is quite possible that human cases of WNV encephalitis and meningoencephalitis have occurred but were not diagnosed or reported in Slovakia. From the diagnostic aspects of WNW infection should be considered laboratory results of cerebrospinal fluid analysis. Positive significant plasmacytosis, moderate pleocytosis in cerebrospinal fluid in patients with meningitis and/or encephalitis should alert to the possibility of WNV infection (16).

Other authors have performed large nationwide crosssectional studies and determined the seroprevalence of WNV antibodies to be $11.1 \%$ in Israel (1), $11 \%$ in Iran (10), 5.2\% in Morocco (17), 4.3\% in Turkey (18), 2.75\% in Libya (19), and $2.1 \%$ in Greece (3).

A group of professional soldiers was an unexpected surprise. Because of their outdoor activities and long-term stays in endemic areas, we expected the highest proportion of positivity to be found in these samples in our study. The finding was in contrast with the study of Cohen et al. (20) performed on 285 healthy soldiers aged $40-55$ years, with $41.9 \%$ IgG positivity.

The risk of WNV seropositivity increased with age over 50 years $(3,18)$. The high seroprevalence in older people reflects the cumulative time of exposure during life to outdoor activities and the risk of being exposed to infected mosquitoes.
People living in rural localities had higher seroprevalence than those living in cities (1). This was similar to our finding that older patients had a positive epidemiological history (repeated mosquitoes bites, stay in an endemic area).

Encephalitis is the most common form of WNV neuroinvasion, followed by meningitis and acute flaccid paralysis. However, Guillain-Barré syndrome and brachial plexus palsy were also reported to be associated with this virus $(7,11,21,22)$. One female patient (Case 2) was treated for monoparesis of UE with the features of plexopathy that could not be better explained by neuroimaging examinations. We cannot prove the causal relation of monoparesis with WNV infection, but we cannot rule it out of the hypothesis either.

Two of the three WNV-positive subjects came from samples of neurological patients, which raises the WNV seropositivity prevalence to $1.6 \%$ in this group and suggests that active screening should be done in patients with peripheral motor neuron disorder that cannot be otherwise explained.

People who live, work or undertake recreational activities in rural, agricultural or horticultural settings are at higher risk of mosquito-borne infections $(1,19)$. We expect a similar exposure to mosquitoes according to one patient's profession (shepherdess) and reported outdoor work activities. In the opposite case, no positivity was detected in gardeners, farm workers and Roma ethnicity, despite their frequent time spent outdoors connected with work and free-time activities.

Positive samples should be systematically confirmed by a plaque reduction neutralization assay, which is considered the gold standard diagnostic method for flavivirus serology. This test has also been adopted by the European Union (EU) case definition (23).

A further aspect to be considered is the cocirculation of WNV and other flaviviruses, sharing the same hosts and ecological niches as the Usutu virus.

In the present study, the positive samples were tested for USUV to eliminate the possibility of cross reactivity with WNV antibodies, with a positive result in one case. USUV is an African mosquito-borne flavivirus belonging to the Japanese encephalitis virus serocomplex (24). In 2009, the first two human cases of USUV infection in Europe were reported in Italy, causing meningoencephalitis in immunocompromised patients (25).

WNV is spreading in Europe and neighbouring countries at an increasing rate, with new lineages and variants emerging into new territories. Several factors, especially urbanisation, variation in land use and climate, seem to be contributing to the current epidemiological picture (5).

As for prevention, there is currently no vaccine against $\mathrm{WNV}$ licensed for human use. Only veterinary WNV vaccines are available on the market. Currently, there are limited treatment options for patients infected with WNV. Only two classical antiviral compounds, interferon and ribavirin, have shown promising results (8).

To mitigate the risk of WNV emergence, targeted public health actions should be taken. As for the preventive activities, WNV surveillance in mosquitoes, birds and horses must be intensified to allow early detection and timely intervention strategies to prevent outbreaks of WNV neurological disease $(2,4,26)$.

A mosquito control programme is carried out continuously throughout the whole year. It consists of the detection and reduction 
of breeding sites as well as routine larviciding in breeding sites that cannot be eliminated. Adulticiding activities are carried out only in small, well-defined areas when the population of mosquitoes reaches critical levels (27).

Another preventive action - the screening of donor blood for WNV RNA is in line with the EC directives 2004/33 (28) and 2014/110 (29).

Elderly people are more prone to be infected and develop WNND, suggesting that those above 65 years of age should be a target group for prevention campaigns among the general population and the health professionals (3).

The established enhanced surveillance of WNV infection among humans and animals, comprehensive vector control and the implementation of the recommended blood safety and hemovigilance measures during the transmission period constitute the basis of successful management of this seasonal public health threat (13).

\section{CONCLUSION}

Since most WNV infections are asymptomatic, a seroprevalence survey is necessary to examine the exposure of the population to the virus and to identify areas with high endemicity.

As there is no available WNV vaccine for humans, the most effective way to avoid WNV infections is to raise the awareness of the population, to reduce the risk of mosquito bites by using insect repellents, to wear protective clothing and to reduce mosquito breeding sites.

The results of the present study are preliminary findings which highlight the current situation in Eastern Slovakia and could be used in future studies. Moreover, given the evidence on WNV circulation in Central European countries, further studies employing a reference method and including both the mammalian hosts and mosquitos are required to obtain data better reflecting the WNV epidemiology in Slovakia, especially in the East.

The integrated collection and analysis of data from humans, animals and vector surveillance is the key to obtain a comprehensive understanding of the epidemiological situation of WNV and consequently timely implementation of response measures.

\section{Ethical Approval}

The study was approved by the Ethics Committee of the Louis Pasteur University Hospital of Košice, and all patients signed written informed consent prior to enrolment.

\section{Acknowledgements}

This work was supported by VEGA Grants No. 1/0198/13, 1/0011/14 and 1/0729/16 of the Ministry of Education, Science, Research and Sport of the Slovak Republic, and the NKFIH K-120118, Lendület (Momentum) project (LP 2012-22). We also thank to the Board of Directors of Louis Pasteur University Hospital in Košice for assistance with organization of sample collection at the hospital wards.

\section{Conflict of Interests}

None declared

\section{REFERENCES}

1. Bassal R, Shohat T, Kaufman Z, Mannasse B, Shinar E, Amichay D, et al. The seroprevalence of West Nile virus in Israel: a nationwide cross sectional study. PLoS One. 2017 Jun;12(6):e0179774. doi:10.1371/ journal.pone.0179774.

2. Rizzo C, Napoli C, Venturi G, Pupella S, Lombardini L, Calistri P, et al. West Nile virus transmission: results from the integrated surveillance system in Italy, 2008 to 2015. Euro Surveill. 2016 Sep 15;21(37). pii: 30340 .

3. Hadjichristodoulou C, Pournaras S, Mavrouli M, Marka A, Tserkezou $\mathrm{P}, \mathrm{Baka} \mathrm{A}$, et al. West Nile virus seroprevalence in the Greek population in 2013: a Nationwide cross-sectional survey. PLoS One. 2015 Nov 25; 10(11):e0143803. doi:10.1371/journal.pone.0143803.

4. Gossner CM, Marrama L, Carson M, Allerberger F, Calistri P, Dilaveris D, et al. West Nile virus surveillance in Europe: moving towards an integrated animal-human-vector approach. Euro Surveill. 2017 May;22(18). pii: 30526.

5. Marcantonio M, Rizzoli A, Metz M, Rosà R, Marini G, Chadwick E, et al. Identifying the environmental conditions favouring West Nile virus outbreaks in Europe. PLoS One. 2015 Mar;10(3):e0121158. doi: 10.1371/journal.pone.0121158.

6. Al-Jabi SW. Global research trends in West Nile virus from 1943 to 2016: a bibliometric analysis. Global Health. 2017 Aug; 13(1):55. doi: 10.1186/s12992-017-0284-y.

7. Jabłońska J, Popiel M, Bukowska-Ośko I, Perlejewski K, Cortés KC, Horban A, et al. No evidence of West Nile virus infection among Polish patients with encephalitis. Cent Eur J Immunol. 2016;41(4):383-5.

8. Pisani G, Cristiano K, Pupella S, Liumbruno GM. West Nile virus in Europe and safety of blood transfusion. Transfus Med Hemother. 2016 May;43(3):158-67.

9. Gaibani P, Pierro A, Lunghi G, Farina C, Toschi V, Matinato C, et al. Seroprevalence of West Nile virus antibodies in blood donors living in the metropolitan area of Milan, Italy, 2009-2011. New Microbiol. 2013 Jan;36(1):81-3.

10. Meshkat Z, Chinikar S, Shakeri M, Manavifar L, Moradi M, Mirshahabi $\mathrm{H}$, et al. Prevalence of West Nile virus in Mashhad, Iran: a populationbased study. Asian Pac J Trop Med. 2015 Mar;8(3):203-5

11. Paphitou NI, Tourvas A, Floridou D, Richter J, Tryfonos C, Christodoulou $\mathrm{C}$. The first human case of neuroinvasive West Nile virus infection identified in Cyprus. J Infect Public Health. 2017;10(6):891-3.

12. Chalupa P, Smith JW, Holub M. Clinical and epidemiological problems of West Nile Fever. Neurol Prax. 2008;9(2):109-11. (In Czech.)

13. Pervanidou D, Detsis M, Danis K, Mellou K, Papanikolaou E, Terzaki I, et al. West Nile virus outbreak in humans, Greece, 2012: third consecutive year of local transmission. Euro Surveill. 2014 Apr;19(13). pii: 20758.

14. Lustig Y, Mannasse B, Koren R, Katz-Likvornik S, Hindiyeh M, Mandelboim M, et al. Superiority of West Nile virus RNA detection in whole blood for diagnosis of acute infection. J Clin Microbiol. 2016 Sep;54(9):2294-7.

15. Public Health Authority of the Slovak Republic. Annual report 2009 [Internet]. Bratislava: Public Health Authority of the Slovak Republic [cited 2017 Sep 13]. Available from: http://www.uvzsr.sk/docs/vs/ VS_UVZ_09.pdf. (In Slovak.)

16. Chalupa $P$. Is the West Nile virus infection diagnosed correctly? Cesk Slov Neurol Neurochir. 2007;70(5):544-6. (In Czech.)

17. El Rhaffouli H, Lahlou-Amine I, Loutfi C, Laraqui A, Bajjou T, FassiFihri O, et al. Serological evidence of West Nile virus infection among humans in the southern provinces of Morocco. J Infect Dev Ctries. 2013 Dec;7(12):999-1002.

18. Gazi H, Özkütük N, Ecemis Ö, Atasoylu G, Köroglu G, Kurutepe S, et al. Seroprevalence of West Nile virus, Crimean-Congo hemorrhagic fever virus, Francisella tularensis and Borrelia burgdorferi in rural population of Manisa, western Turkey. J Vector Borne Dis. 2016 AprJun;53(2):112-7.

19. Shaibi T, Saadawi WK, Aghila H, Annajar BB. Prevalence of IgG antibodies for the West Nile virus in human population in Tripoli, Libya. J Vector Borne Dis. 2017 Apr-Jun;54(2):183-6.

20. Cohen D, Zaide Y, Karasenty E, Schwarz M, LeDuc JW, Slepon R, et al. Prevalence of antibodies to West Nile fever, sandfly fever Sicilian, and sandfly fever Naples viruses in healthy adults in Israel. Public Health Rev. 1999;27(1-3):217-30.

21. Chahil M, Nguyen TP. West Nile virus-associated brachial plexopathy. BMJ Case Rep. 2016;2016. pii: bcr2016214428. 
22. Scholz S, Kaas B, Simpkins A, Lyons J, Venkatesan A, Probasco J. Brachial plexitis preceding encephalomyelitis in a patient with West Nile virus infection. BMJ Case Rep. 2013 Dec;2013. pii: bcr2013200833.

23. Commission implementing Decision of 8 August 2012 amending Decision 2002/253/EC laying down case definitions for reporting communicable diseases to the Community network under Decision No 2119/98/EC of the European Parliament and of the Council. Off J Eur Union. 2012 Sep 27;55(L 262):1-57.

24. Ashraf U, Ye J, Ruan X, Wan S, Zhu B, Cao S. Usutu virus: an emerging flavivirus in Europe. Viruses. 2015 Jan;7(1):219-38.

25. Pecorari M, Longo G, Gennari W, Grottola A, Sabbatini A, Tagliazucchi $\mathrm{S}$, et al. First human case of Usutu virus neuroinvasive infection, Italy, August-September 2009. Euro Surveill. 2009 Dec;14(50). pii: 19446.

26. Fros JJ, Geertsema C, Vogels CB, Roosjen PP, Failloux AB, Vlak JM, et al. West Nile virus: high transmission rate in north-western european mosquitoes indicates its epidemic potential and warrants increased surveillance. PLoS Negl Trop Dis. 2015 Jul 30;9(7):e0003956. doi: 10.1371/journal.pntd.0003956
27. Klobucar A, Benic N, Krajcar D, Kosanovic-Licina ML, Tesic V, Merdic E, et al. An overview of mosquitoes and emerging arboviral infections in the Zagreb area, Croatia. J Infect Dev Ctries. 2016 Dec 30;10(12):1286-93.

28 Commission Directive 2004/33/EC of 22 March 2004 implementing Directive 2002/98/EC of the European Parliament and of the Council as regards certain technical requirements for blood and blood components. Off J Eur Union. 2004 Mar 30;47(L 91):25-39.

29. Commission Directive 2014/110/EU of 17 December 2014 amending Directive 2004/33/EC as regards temporary deferral criteria for donors of allogeneic blood donations. Off J Eur Union [Internet]. 2014 Dec 20 [cited 2018 Aug 20];57(L 366):81-2. Available from: http://data.europa. eu/eli/dir/2014/110/oj.

Received December 19, 2017 Accepted in revised form August 20, 2018 